\title{
Epidemiological investigation into the re-emergence and control of an outbreak of infectious salmon anaemia in the Shetland Islands, Scotland
}

\author{
Alexander G. Murray*, Lorna A. Munro, I. Stuart Wallace, Barbara Berx, \\ Daniel Pendrey, David Fraser, Rob S. Raynard
}

Marine Laboratory, Marine Scotland Science, 375 Victoria Road, Aberdeen, AB11 9DB, UK

\begin{abstract}
Infectious salmon anaemia (ISA) is an orthomyxoviral disease, primarily affecting marine-phase farmed Atlantic salmon, which can result in high levels of mortality. ISA first emerged in Norway in the 1980s and subsequently has occurred in Canada, the USA, the Faeroe Islands and Chile. An outbreak occurred in Scotland in 1998-1999, but was eradicated at a cost of over £20M. The epidemiology of a new outbreak of ISA in the Scottish Shetland Islands during 2008-2009 is described. Six sites have been confirmed ISA-positive. Spread of the virus via transport of fish between marine sites, harvest vessels, smolts and wild fish appears to have been of little or no importance, with spread primarily associated with marine water currents. The use of management areas by Marine Scotland to control the event appears to have been effective in restricting spread to a small area. This localised outbreak contrasts with the 1998-1999 outbreak that spread over a wide geographic area with transported fish and harvest vessels. The development and application of industry codes of good practice, good husbandry and biosecurity practices, limited marine site-to-site movement of live fish and improved disinfection of vessels and processing plant waste that occurred subsequent to the 1998-1999 outbreak may explain the localised spread of infection in 2008-2009. Depopulation of confirmed sites has been achieved within $7 \mathrm{wk}$ (mean $=3.7 \mathrm{wk}$ ); however, it is likely that subclinical infection persisted undetected for months on at least 1 site. The origin of the 2008-2009 outbreak remains unknown. Potential sources include evolution from a local reservoir of infection or importation. Synchronous fallowing of management areas, with good husbandry and biosecurity, reduces the risk of ISA recurring. Movement of fish between sites in different management areas represents the greatest risk of regional-scale spread, should this occur.
\end{abstract}

KEY WORDS: Infectious salmon anaemia · ISA · Epidemiology · Control · Eradication Hydrodynamics $\cdot$ Harvest $\cdot$ Scotland

\section{INTRODUCTION}

Infectious salmon anaemia (ISA) is a highly infectious orthomyxoviral (ISAV) disease of farmed Atlantic salmon Salmo salar that was first reported in Norway in 1984 and has caused major losses to salmon farmers in Norway, Scotland, Canada, the USA, the Faeroe Islands and Chile (OIE 2009). An outbreak occurred in Scotland in 1998-1999 (Joint Government/Industry Working Group on ISA 2000, Stagg 2003) which was eradicated at a cost then of over £20M (Hastings et al.
1999). During this outbreak, ISA was confirmed at 11 sites with additional suspect sites scattered across a wide geographic area of Scottish waters containing salmon farms before its eventual eradication (Stagg 2003).

In 2008-2009 a further outbreak of ISA occurred (Anonymous 2009); this outbreak was geographically confined to a relatively small area in southwest Shetland (Fig. 1) within which 6 salmon farm sites were confirmed ISA-positive. In the present study, we describe the outbreak and epidemiological processes 


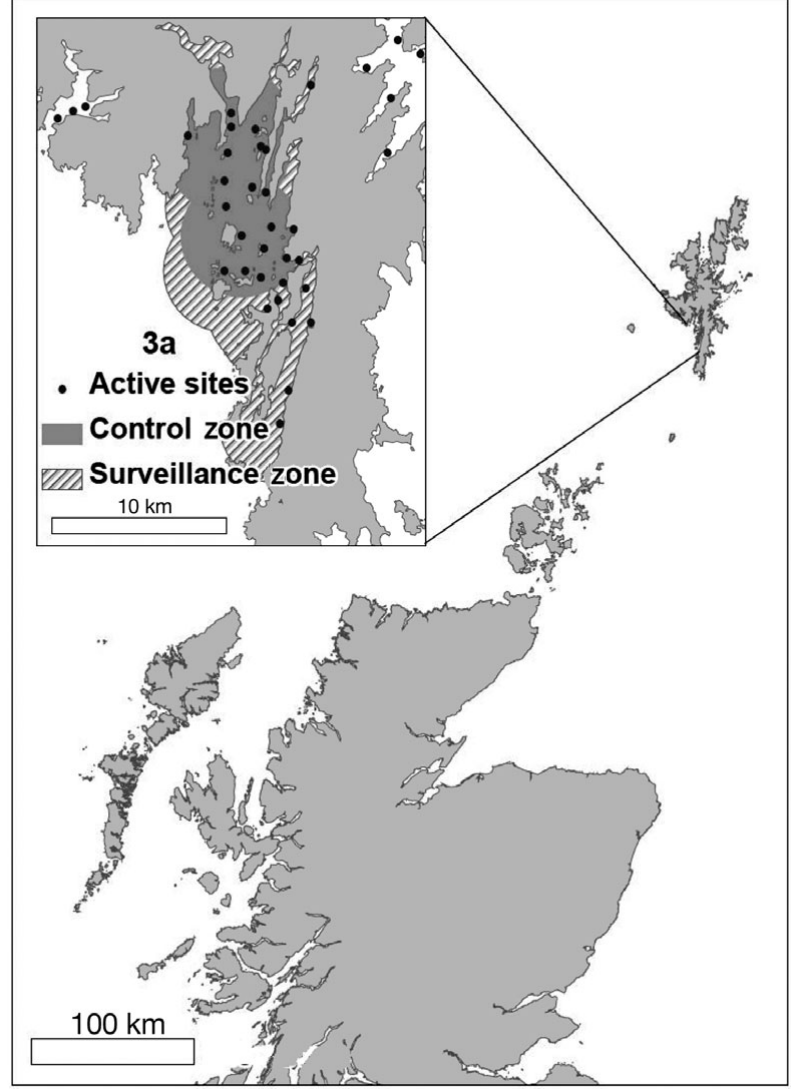

Fig. 1. Management Area 3a (MA 3a), Scotland. The entire MA became a surveillance zone. A control zone initially surrounded index Site A and 2 suspect sites (not marked) and expanded as further cases were confirmed

behind ISA spread and how current Scottish fish farming structures and practices led to the spatial limitation of such spread, thus creating the conditions under which ISA could be controlled and eradicated.

In 2008, Scotland produced 128606 metric tonnes (t) of farmed Atlantic salmon from 257 marine sites and $2628 \mathrm{t}$ of sea-farmed rainbow trout Oncorhynchus mykiss from 9 sites (Walker 2009). A further $311 \mathrm{t}$ of brown and sea trout (both Salmo trutta) were also produced, but separate statistics are not published for marine and freshwater farms. (Both O. mykiss and $S$. trutta can carry the virus but do not develop clinical ISA [OIE 2009]). A third of Scottish salmon production (42593 t) came from the Shetland Islands.

Scottish salmon production is divided for the purposes of disease control into management areas (MAs) (Marine Scotland 2009). These MAs use a radius of $3.6 \mathrm{~km}$ around a fish farm in Shetland $(7.2 \mathrm{~km}$ for fish farms elsewhere in Scotland), which is partly based on a simple but robust tidal model (Stagg 2003). An MA extends until neighbouring radii cease to overlap (i.e. a gap of $>2 \times 3.6 \mathrm{~km}$ is reached). These MAs were originally devised as part of the controls for the 1998-1999
ISA outbreak (Stagg 2003) and simple modelling indicates they are likely to be appropriate for ISA control, if not for other pathogens (Murray et al. 2005). On confirmation of infection, movement of fish in and out of affected MAs is prohibited; however, in the absence of confirmation, movements may proceed, although by industry codes of practice (CGPWG 2006) all seawaterto-seawater movement should be subject to a risk assessment.

ISA in 2008-2009 was confined to one MA in southwest Shetland: MA 3a (Fig. 1). MA 3a is the largest in Scotland (Marine Scotland 2009) and produced over $10 \%$ of Scotland's farmed salmon in 2007. This MA contained 27 salmon producing sites, 1 sea trout producing site and 2 sites holding non-susceptible finfish species, one containing halibut Hippoglossus hippoglossus and the other a tank-based research site containing both ballan wrasse Labrus bergylta and goldsinny wrasse Ctenolabrus rupestris. MA 3a contains a fish processing plant at the port of Scalloway, although fish from MA 3a are also routinely processed at a plant in Lerwick on the east coast of Shetland.

ISAV can be spread with the transport networks of live fish (Munro \& Gregory 2009) and with harvesting operations (Munro et al. 2003), and hence can be associated with well boat movements (Murray et al. 2002) and anthropogenic activities, possibly over a large area. ISAV may also be spread in the environment by wild fish (Nylund \& Jakobsen 1995) and with water currents (Gustafson et al. 2007). The virus is transmitted via water even in the absence of clinical disease (Totland et al. 1996); however, viral shedding is increased 2 d before death (Gregory et al. 2009). This local transmission is likely to result in the infection risk being clustered. Jarp \& Karlsen (1997) identified an enhanced risk of infection (odds ratio 8) if infected farms were within $5 \mathrm{~km}$ of the farm assessed, the odds increasing as the distance decreased. Scheel et al. (2007) and Lyngstad et al. (2008) have also identified proximity as a risk factor.

These modes of transport are effective over different distances and result in a variety of patterns of spread. In the present study, the significance of different forms of spread is assessed in the light of the outbreak pattern and data on contact distributions implied by these different routes. This is used to investigate why ISA was confined to MA $3 \mathrm{a}$ and to assess processes that may significantly undermine the control strategy.

\section{MATERIALS AND METHODS}

Detection of ISA. Surveillance: Fish Health Inspectors (FHIs) from the Marine Scotland Marine Laboratory undertake annual visual inspections of finfish 
farms, taking full diagnostic samples from any fish showing gross signs of disease. These farms are sampled every second year irrespective of there being any signs of disease (OIE 2009, EU Council Directive 2006/88/EC). Where suspicion of a notifiable disease, ISA or otherwise, is raised from the results of the initial diagnostic investigation, statutory samples for ISAV are taken from 150 fish to confirm or rule out disease presence. Intelligence-led surveillance is also implemented with sites subjected to diagnostic investigation including sampling of 5 to 10 fish following reports of health problems or mortality. If results indicate ISA infection, FHIs return for statutory samples of 150 fish. Due to ISA being notifiable, passive surveillance is also undertaken so veterinarians, fish farmers and others are obliged to report suspicion of its presence (Aquatic Animal Health Scotland Regulations 2009). Sites that receive fish from ISA-confirmed sites are automatically classified as officially suspect.

Following confirmation of ISA on 2 January 2009, a surveillance zone was set up covering the whole of MA $3 \mathrm{a}$, within which a control zone surrounded the confirmed and suspect sites by one radius (Fig. 1). An initial 150 fish samples were taken at all susceptible sites within the control zone. Thereafter, monthly inspections at all sites within the control zone and bi-monthly inspections at all sites within the outlying surveillance zone were undertaken. If signs of disease, including elevated mortality $\left(>0.05 \% \mathrm{wk}^{-1}\right.$ in the worst-affected cage), were evident (OIE 2009), a diagnostic (5 to 10 fish) sample was taken and, if results indicated but did not confirm infection, a further 150 fish were taken. Sites in other MAs that had had possible contacts with MA 3a, including sites where fish had been moved to or from MA 3a and a site near a processing plant that had processed fish from MA 3a, were also subjected to 150-fish tests and bimonthly inspections.

Diagnosis of ISA: Diagnosis of ISA was carried out using the samples described above from clinical and gross signs, full histology, quantitative real-time PCR (qPCR) and virus isolation (OIE 2009). These diagnostic methods are largely based on the established OIE standards, though the qPCR has been refined (Snow et al. 2009); to avoid false positives, 3 replicates of each sample were tested and all must be positive to confirm the qPCR. The disease was confirmed on a particular farm by clinical signs and gross pathology consistent with ISA supported by qPCR or virus isolation, both qPCR and virus isolation, or virus isolation from 2 independent samples.

Tissues from 5 farmed fish were pooled to minimise diagnostic costs for qPCR and virus isolation. However, on some occasions diagnostic samples consisted of a few moribund individuals so smaller pools or individual fish were sometimes screened.
Virus isolation, tested in North America, was found to be effectively $100 \%$ specific for ISAV but is slower (approximately $3 \mathrm{wk}$ ) and less sensitive (88.7\%) than reverse transcription PCR (RT-PCR; $93 \%$ ) (Nérette et al. 2008). However, RT-PCR was estimated as $99 \%$ specific, which means significant numbers of false positive results are possible when large numbers of fish are sampled. Diagnostic methods, and the ISA virus, in Scotland differ in details from those tested by Nérette et al. (2008) so Scottish values of sensitivity and specificity may also be different. Positive qPCR results can be generated by the avirulent HPR0 forms of ISAV (McBeath et al. 2009); therefore, unsupported qPCRs were treated as false positives if they could not be confirmed by other diagnostic tests or indicators of ISAV.

Control of ISA: On suspicion of ISA, movement restrictions are placed on the site for $30 \mathrm{~d}_{\text {; following }}$ confirmation, movement restrictions are imposed on all sites within the MA and the surveillance regime described above is implemented. In Scotland, confirmed sites are depopulated, but in other countries depopulation may be restricted to cages with significant mortality. McClure et al. (2004) showed that the prevalence of ISAV in non-moribund fish was the same whether or not mortality occurred in a sampled cage, providing ISA was present on the farm. Depopulation was undertaken on the basis of epidemiological evidence to provide a policy of eradication for which requirements to achieve are described in EU Council Directive 2006/88/EC.

Potential routes of spread. Movements of fish and harvest vessels: Live fish movements are a high risk for spreading pathogens (Munro \& Gregory 2009, Murray $\&$ Peeler 2005) and therefore the records of fish movements between sites have been collected to determine if they contributed to the spread of ISAV within MA 3a and to other MAs. These records have been used to develop a contact network that identifies the sites between which fish were transported. The test results are plotted to identify if there is any association between infected sites that is reflected in the transport network.

Harvest vessels can spread ISAV (Murray et al. 2002, Munro et al. 2003). Two processing plants were used to harvest fish obtained from within MA 3a, one at Scalloway (SPP) within MA 3a, and the other at Lerwick (LPP) on the east coast of Shetland. The FHIs therefore obtained the logs of vessels involved in transporting fish between sites in MA 3a and these processing plants. These plants were also visited by FHIs to assess biosecurity and disinfection regimes as a failure of these could have the potential to contaminate the surrounding waters and hence, potentially, visiting vessels. 
Vertical transmission: There is disagreement as to whether ISAV is vertically transmitted (Lyngstad et al. 2008, Vike et al. 2009). If vertical transmission did occur then this could be significant both as a potential source of the Shetland outbreak, since imported ova are used (although these are certified ISAV-free), and as a potential route of spread within Scotland and beyond via Shetland-reared broodstock. It is also possible that ISAV could be transmitted on the outside of poorly disinfected eggs (pseudovertical transmission). Therefore, the sources of input of smolts to Shetland and the potential exposure of ova that were produced from broodstock within Shetland are assessed.

Wild fish: Wild fish, especially salmonids, can carry ISAV (Nylund \& Jakobsen 1995, Raynard et al. 2001). Two surveys of local wild fish were conducted: one of wild marine fish from within MA 3a, and the other of anadromous and freshwater fish, including salmonids, in surrounding rivers draining into MA 3a (Wallace et al. 2009). The wild marine survey consisted of repeated trawls from 3 locations from 9 to 11 February 2009. The freshwater survey was undertaken from 23 to 25 March 2009 using electrofishing. The later sampling date for this survey was chosen to allow the freshwater temperatures to warm up. From previous personal experience (I. S. Wallace) these higher temperatures make the fish more active, thus increasing the chances of catching them. Additionally, there was a greater chance of catching migratory sea trout returning to freshwaters at this time of year (Wallace et al. 2009).

Wild marine fish were mostly pooled in groups of 5 with a few exceptions of smaller pools or individual fish depending on the numbers caught. Fish from the freshwater survey were individually sampled. The gill, kidney, heart and brain were separately collected from each fish. For the marine survey these individual organs were separately pooled, e.g. a pool of heart material from 5 fish. From the freshwater survey the organs from each fish were individually stored. The organ samples were screened for ISAV using the qPCR testing procedure (Wallace et al. 2009).

Additionally, 2 saithe Pollachius virens obtained from within a cage containing salmon clinically infected with ISA were opportunistically sampled. Individual organs were collected as described above and screened for ISAV using qPCR.

Hydrodynamic spread: Hydrodynamic spread between sites in a neighbourhood is likely to result in clustered infection centred around the index case. Therefore, the locations of the infected sites were mapped and the excursion radius distance (Stagg 2003) around these sites used to identify the potential for hydrodynamic transport between affected sites.

\section{RESULTS AND DISCUSSION}

\section{Origins of the outbreak}

There are 3 possible origins for the ISA virus affecting Shetland: (1) spontaneous evolution from an avirulent wild type virus (Nylund et al. 2003); (2) introduction from abroad; or (3) the undetected persistence of the 1998-1999 virus.

The virus responsible for the 2008-2009 outbreak belongs to genogroup 1 (M. Snow pers. comm.), while the 1998-1999 virus was of genogroup 3 (Nylund et al. 2007) and mortality took longer to occur in salmon experimentally challenged with the 2008 virus (K. Urquhart unpubl. data). Hence, the virus genotypes behind the 2 outbreaks were different. Further work on the phylogeny of the virus and its variation between affected sites is being undertaken by Marine Scotland scientists.

Evolution of virulence in ISAV is associated with a deletion mutation (Nylund et al. 2003); the avirulent HPR0 ISAV, which is the putative ancestor of virulent ISAV (Nylund et al. 2003), has been found in Scottish salmon farms (McBeath et al. 2009). While individual sites were fallowed, MA 3a was not synchronously fallowed following the 1998-1999 outbreak and, therefore, at the MA level, was continuously stocked. In 1998, ISA was confirmed at one site in MA $3 a$, and officially suspect on 2 others, but only the sites within $3.6 \mathrm{~km}$ of these affected sites were required to fallow synchronously. Fallowing can be used to prevent viruses from circulating over many generations until virulent forms emerge (Murray \& Peeler 2005). Other pathogens had become widespread in MA 3a, potentially leaving fish more vulnerable to secondary infection by ISAV as, for example, pancreas disease outbreaks have been shown to be associated with high sea lice burdens (Rodger \& Mitchell 2007). However, pre-existing viral infections such as infectious pancreatic necrosis virus (IPNV) can increase immunity (Johansen \& Sommer 2001). The 1998-1999 ISA outbreak emerged on a site that had multiple generations of salmon (Stagg 2003), underlining the need for fallowing.

It is possible that international trade could have introduced ISAV to Shetland. Live fish were not imported, nor were fish for processing at the SPP. Vessels servicing the plant are locally based (see 'Harvest operations') and so would not act as international vectors. However, Norwegian ova are widely used in Scotland, including for the production of some of the smolt stock for the putative index site, and so were investigated as a potential transmission route. Yet, the epidemiology of this outbreak of ISA indicates it emerged late in the production cycle (see 'Fish moved between sites'), indicating virulent ISAV was not introduced with ova. 


\section{Chronology of the outbreak}

When ISA was confirmed, there were 12 stocked salmon sites (of 28 active sites), 1 trout site and 1 nonsusceptible halibut site in MA 3a. Additionally, a tankbased research site held small numbers of non-susceptible ballan and goldsinny wrasse. The salmon and trout farms contained a single year class of fish and were fallowed before another age class was moved on. The history of site testing is tabulated and mapped in Table 1 and Fig. 2, respectively; only qPCR and virology results from the last diagnostic test are listed for each site. Sites B to m, were tested for ISA in January 2009; all except Site B were negative, although Site F returned an unsupported positive qPCR (see 'Diagnosis of ISA' $^{\prime}$ ).

FHIs visited Site A on 9 December 2008 as part of an investigation into fish health problems ascribed to sea lice Lepeophtheirus salmonis; high sea lice burdens can be associated with disease emergence (Rodger \& Mitchell 2007). Diagnostic sampling at the site resulted in a positive GPCR for ISAV, so the site was revisited and 150 fish were sampled. ISA was confirmed by qPCR (8/30 pools) and virology (7/30) on 2 January 2009; however, the site had already been harvested on 20 December (Fig 2a).

Fish from Site A had been moved to 2 other sites (see Fig. 3) and so these were automatically placed under official suspicion. One of these sites had already been harvested (and so is not named in Table 1), and the other (Site g) was screened negative (Table 1).
Five sites $(\mathrm{g}-\mathrm{k})$ were harvested during January 2009 and all of these had tested ISAV-negative. Thus, half the salmon sites in MA 3a that had been populated in December 2008 were harvested by the end of January 2009 (Fig. 2b).

There were diagnostic indications of ISAV at 2 sites during January 2009, but these tested negative. At one (Site D) there was a positive reaction in 2 of 3 replicates from one pool by qPCR. A lack of reproducibility classed the test result as negative according to the accredited diagnostic testing procedure; however, this could indicate exposure to ISAV infection. Five months later, Site D tested positive (18 May), becoming the fourth confirmed site. The other site, Site F, tested positive by qPCR on 7 January; however, this was not confirmed by virology. A subsequent statutory 150-fish test on 13 January was negative by both qPCR and virology. This site eventually tested positive and this time was confirmed at the end of October 2009 during harvesting. Even if these sites were infected, because they were under movement restriction and enhanced surveillance, their classification as negative was considered a low risk. However, one interpretation of their subsequent histories may be that Sites D and F were carrying low levels of infection.

During January 2009, Site B became the second confirmed case of ISA and Site C, adjacent to positive Site B, became the third on 20 March (Fig. 2c). Another site, Site 1, was harvested normally on 25 February.

The sea trout at Site m were culled on 2 April for welfare reasons. This site was located in shallow water

Table 1. Chronology of the infectious salmon anaemia (ISA) outbreak with date of positive sample or last negative sample before harvest. Only quantitative PCR (qPCR) and virology (V) results (numbers of positive pools divided by number of pools sampled; pools of 5 fish) are included, other diagnostic results may be available. Sites harvested before testing began are not listed. Sites D and F additionally gave positive or partially positive qPCR results in January 2009; however, these samples were ISAV-negative

(see 'Diagnosis of ISA'). Sites with lower case letters did not test positive for ISA. C1-C6: companies 1-6; na: not applicable

\begin{tabular}{|c|c|c|c|c|c|c|c|}
\hline Site & Owner & $\begin{array}{l}\text { Common } \\
\text { name }\end{array}$ & $\begin{array}{l}\text { Last date sampled } \\
\text { (dd/mm/yyyy) }\end{array}$ & $\begin{array}{l}\text { Date confirmed } \\
\text { (dd/mm/yyyy) }\end{array}$ & Test result & $\begin{array}{c}\text { Date } \\
\text { depopulated }\end{array}$ & $\begin{array}{l}\text { No. of fish on } \\
\text { site at end } 2008\end{array}$ \\
\hline A & $\mathrm{C} 1$ & Salmon & $16 / 12 / 2008$ & 02/01/2009 & qPCR 8/30 V 7/30 & $20 / 12 / 2008$ & $87000^{\mathrm{a}}$ \\
\hline B & $\mathrm{C} 2$ & Salmon & $12 / 01 / 2009$ & $30 / 01 / 2009$ & qPCR 4/30 V 8/30 & 06/03/2009 & 316000 \\
\hline $\mathrm{C}$ & $\mathrm{C} 2$ & Salmon & $18 / 03 / 2009$ & $20 / 03 / 2009$ & qPCR 16/30 V 15/30 & 08/04/2009 & 263000 \\
\hline $\mathrm{D}$ & $\mathrm{C} 2$ & Salmon & $14 / 05 / 2009$ & $18 / 05 / 2009$ & qPCR 1/1 V 1/1 & 02/07/2009 & 284000 \\
\hline $\mathrm{E}$ & $\mathrm{C} 3$ & Salmon & $19 / 05 / 2009$ & $21 / 05 / 2009$ & qPCR 25/30 V 26/30 & $27 / 05 / 2009$ & 6000 \\
\hline F & $\mathrm{C} 4$ & Salmon & $28 / 01 / 2009$ & $30 / 10 / 2009$ & qPCR 1/1 V 1/1 & $25 / 11 / 2009$ & 286000 \\
\hline g & $\mathrm{C} 1$ & Salmon & 06/01/2009 & na & qPCR 0/30 V 0/30 & 07/01/2009 & 297000 \\
\hline $\mathrm{h}$ & $\mathrm{C} 1$ & Salmon & 08/01/2009 & na & qPCR 0/2 & $14 / 01 / 2009$ & 178000 \\
\hline i & $\mathrm{C} 2$ & Salmon & $14 / 01 / 2009$ & na & qPCR 0/30 & $16 / 01 / 2009$ & 301000 \\
\hline $\mathrm{j}$ & $\mathrm{C} 1$ & Salmon & $17 / 01 / 2009$ & na & qPCR 0/30 & $20 / 01 / 2009$ & 249000 \\
\hline $\mathrm{k}$ & $\mathrm{C} 4$ & Salmon & $16 / 01 / 2009$ & na & qPCR 0/30 & 28/01/2009 & 60000 \\
\hline 1 & $\mathrm{C} 2$ & Salmon & $13 / 01 / 2009$ & na & qPCR 0/30 & $25 / 02 / 2009$ & 250000 \\
\hline $\mathrm{m}$ & C5 & Trout & 29/01/2009 & na & qPCR 0/30 & 02/04/2009 & 142000 \\
\hline $\mathrm{n}$ & C6 & Halibut & na & na & na & $27 / 04 / 2009$ & 6000 \\
\hline $\mathrm{o}$ & C3 & Wrasse & na & na & na & na & 380 \\
\hline
\end{tabular}



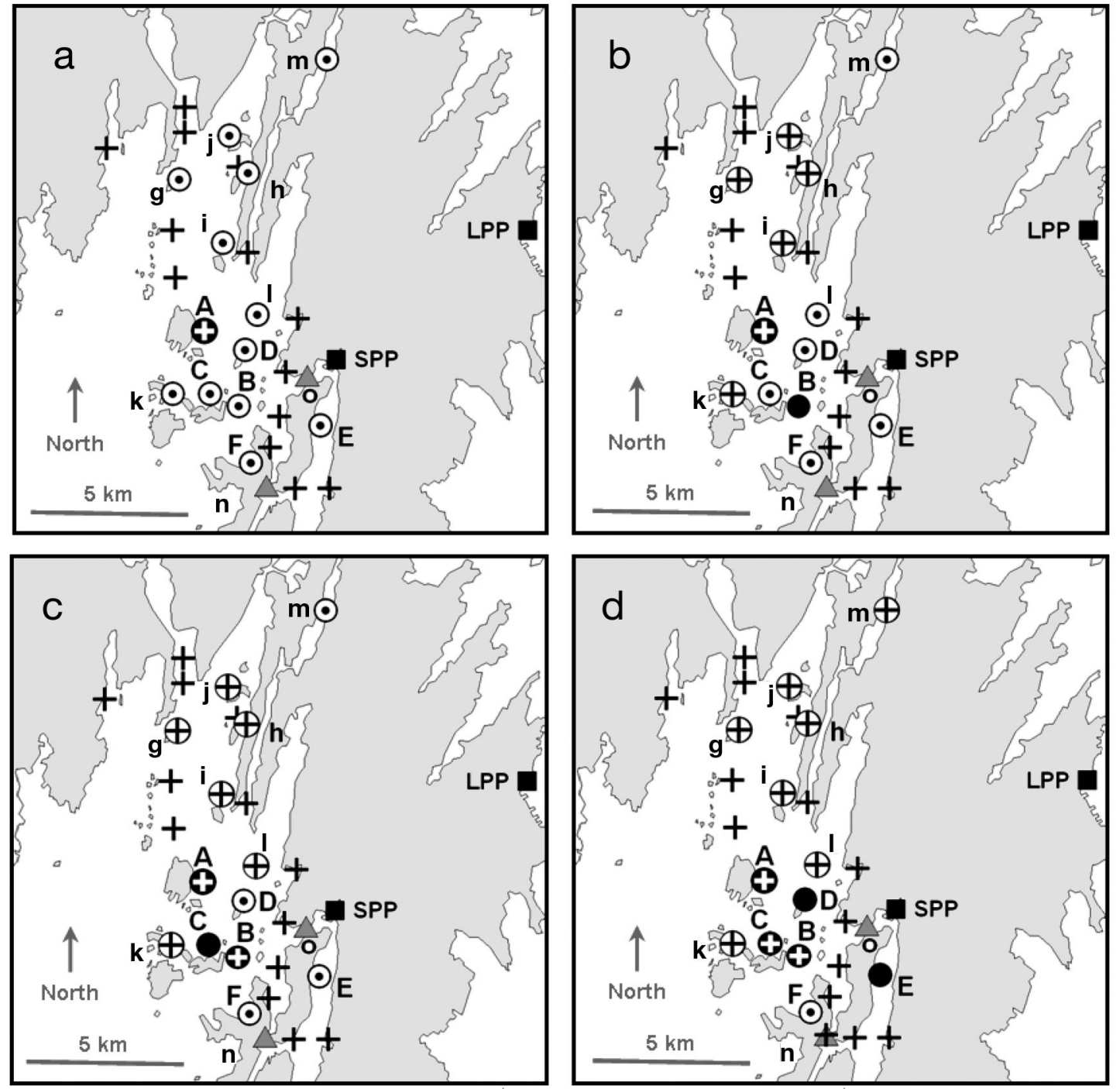

Fig. 2. Chronology and spread of the infectious salmon anaemia (ISA) disease during outbreak 2008-2009 in management area 3a on: (a) 31 December 2008; (b) 31 January 2009; (c) 31 March 2009 and (d) 25 May 2009. Letters refer to sites listed in Table 1. SPP: Scalloway processing plant; LPP: Lerwick processing plant; (+) depopulated before outbreak (not listed);

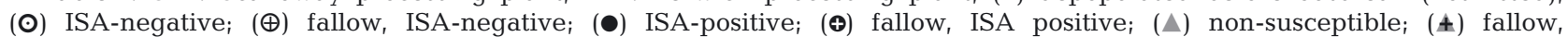
non-susceptible; (匹) processing plant

and, as temperatures increased and the fish increased in weight, the risk of stress was exacerbated. Traditionally, these trout were moved to a site in a different MA, but ISA movement restrictions prohibited this. Site n, containing non-susceptible halibut, was also harvested in April 2009.

A fourth salmon site, Site D, was confirmed ISA-positive on 18 May (Fig. 2d). This was confirmed rapidly on the basis of qPCR (1/1 pools), indirect tissue imprint fluorescent antibody test (IFAT) (2/2 pools) and light microscopy, and later by virology. At nearly the same time (21 May), a small research site, Site E, was confirmed on the basis of samples taken on 19 May (25/30 pools by qPCR, 26/30 pools by virology and 12/12 fish by histology). Site E was sampled after a veterinarian reported signs consistent with ISA.

By 3 July 2009, the only site in MA 3a stocked with susceptible fish was Site F. This site gave an unsupported positive qPCR result (7 January), but despite being subjected to monthly visual surveillance there was no sign of ISA until harvesting began in late October. Confirmation on 30 October was based on qPCR and clinical signs, and later confirmed by light microscopy and virology. As no other sites were populated with susceptible species for the proceeding $4 \mathrm{mo}$, it is likely infection persisted undetected at Site F for at least this period.

Depopulation of the final site holding salmon (Site F) was achieved in November 2009. After this there were 
no susceptible species of farmed fish being held in MA $3 a$; only small numbers of non-susceptible fish that were held in tanks at Site o.

Site depopulation was carried out within 7 wk of confirmation (Table 1). The index case had already been harvested out for $13 \mathrm{~d}$ at the time of its confirmation. Cases B to F were harvested, respectively, 35, 19, 45, 6 and $26 \mathrm{~d}$ after confirmation (mean $26 \mathrm{~d}=3.7 \mathrm{wk}$ ). This 3.7 wk may be compared with a mean 21 wk in Chile (Mardones et al. 2009), where ISA became widespread in the industry. However, a $3 \mathrm{wk}$ mean removal time was achieved in 1998-1999 (Stagg 2003). Subclinical infection may have been present on sites for months; the absence of any other populated sites that Site F was subclinically infected at least from July to October 2009.

A total of 15 sites within Shetland but outside MA 3a were tested in 2009 (up to 15 October) by qPCR, 12 of these were also tested by virology. All samples were negative by both methods.
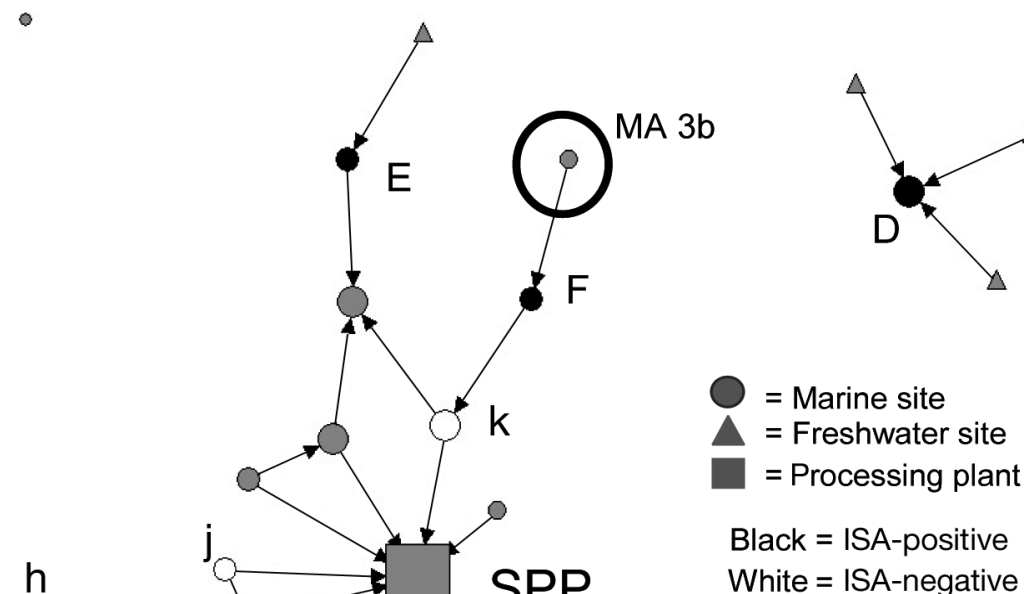

$=$ Processing plant

Black $=$ ISA-positive

White = ISA-negative

Grey = Untested could have acted as sources of infection suggests that

\section{Potential routes of spread}

Fish moved between sites

There is a high risk of spreading disease by moving live fish from infected sites. The movements of fish within, into and out of MA 3a have been used to develop a contact structure network (Munro \& Gregory 2009; Fig. 3). The results show a lack of relationship between movements of fish and cases of ISA with all confirmed sites being disconnected from each other via such movements.

There were movements of live fish from Site A to Site g up to 27 June 2008, but Site g tested negative for ISAV in January 2009. Since the movement of fish is high risk, virulent ISAV is likely to have been absent or, if present, at very low levels at Site A before 27 June 2008. Even if infection had been subclinical at that stage, transport of live fish would very likely have carried the virus to Site $g$ (this is the reason for the use of quarantine in disease control).
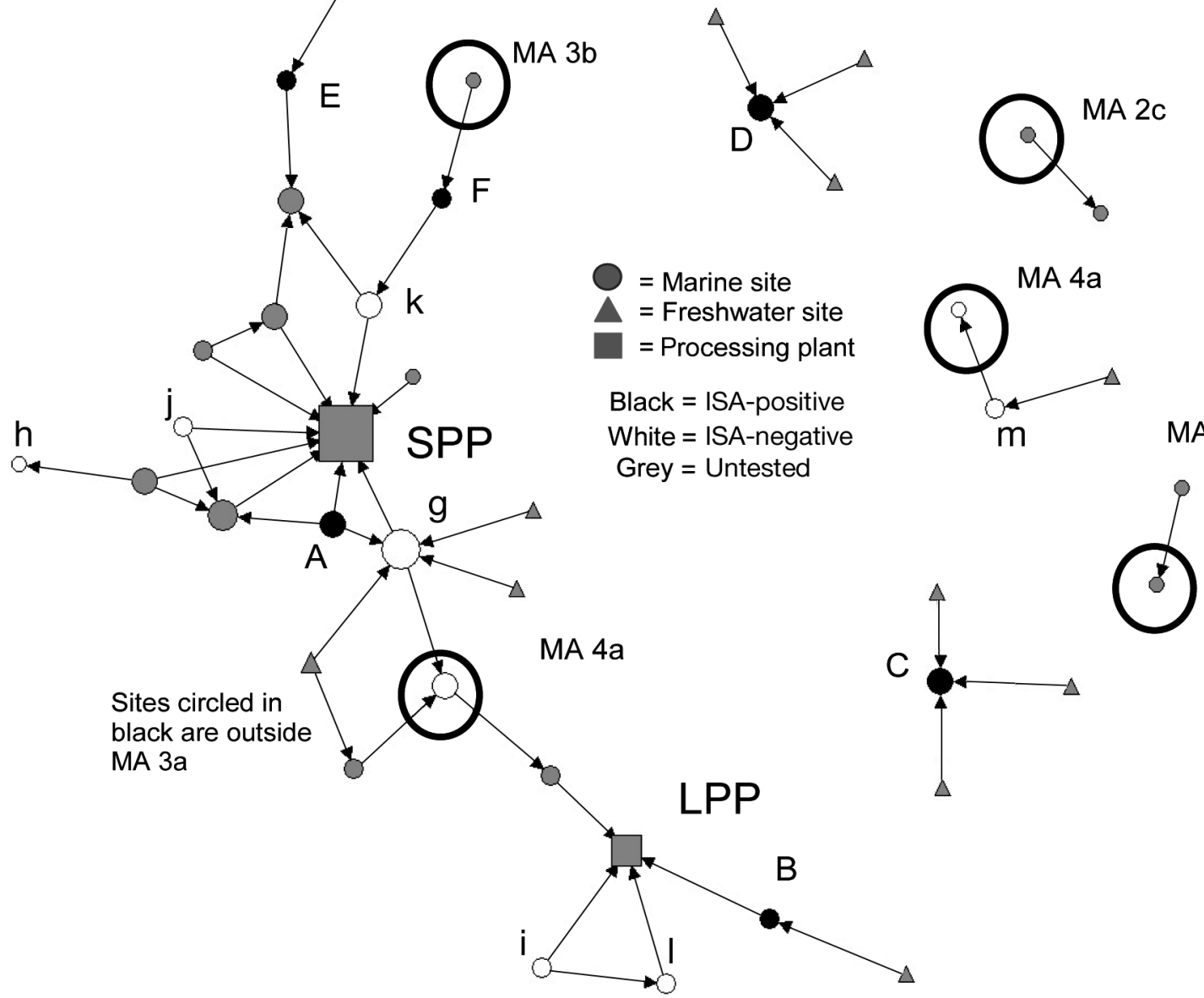

Fig. 3. Structure of network for movements involving salmon and trout in management area (MA 3a) in the year prior to confirmation of ISA. Sites circled in black are located outside MA 3a. Symbol sizes are proportional to the number of other sites contacted. Letters refer to sites listed in Table 1. SPP: Scalloway processing plant; LPP: Lerwick processing plant 
There were no movements of live fish from any sites in MA 3a after 27 June 2008 (except for harvest, see 'Harvest operations'). There were, however, 12 seawater-to-seawater movements within MA 3a before 27 June 2008. There were also movements to and from sites outside the affected MA. Live fish were moved to MAs $4 \mathrm{a}$ and $2 \mathrm{~b}$ and from MAs $4 \mathrm{a}, 3 \mathrm{~b}$ and 2c (Figs. 3 \& 4). If ISAV was not present before June these fish movements could not have spread it; however, the sites outside MA 3a were visited by FHIs to confirm the absence of ISAV and, where fish remained on site, 150 fish samples were taken. The apparent lack of spread supports the view that ISAV was not present elsewhere (i.e. other than Site A) in MA 3a before June 2008.

One movement of live fish was undertaken on 6 October 2008 from MA 3b to a site in MA 3a; by this time ISAV might have been present. This movement of fish was from a site outside the affected MA into the affected MA and therefore was a far lower risk than a movement in the opposite direction.

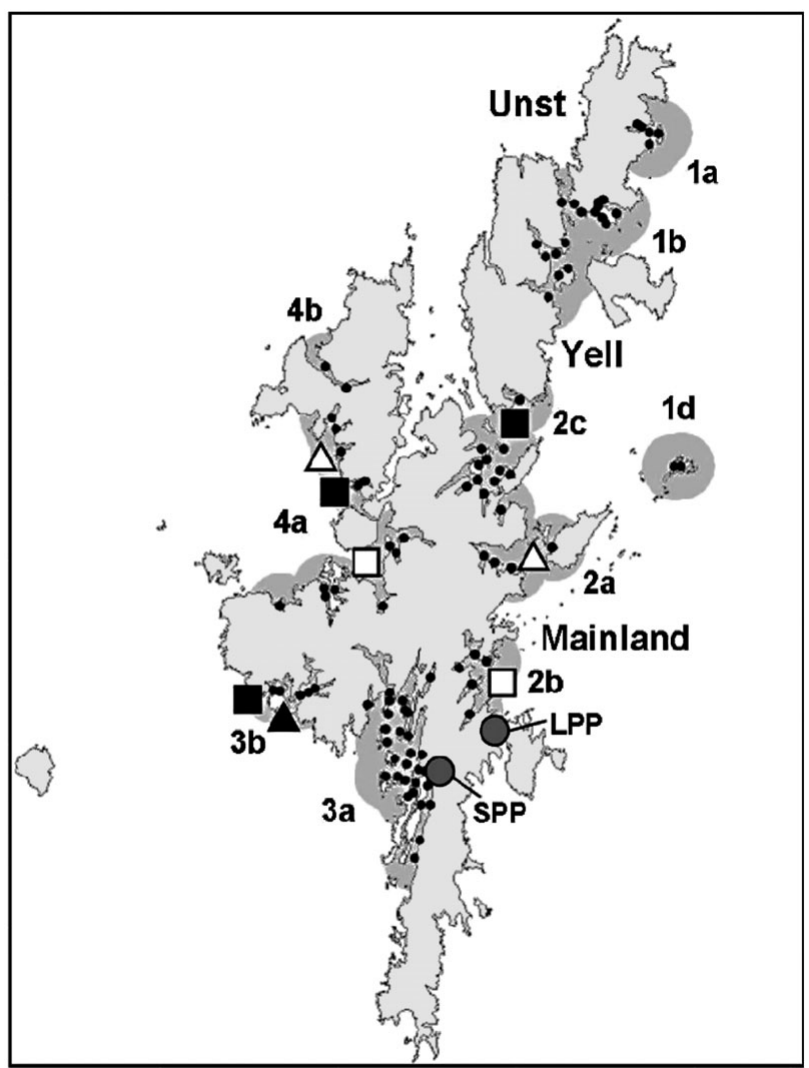

Fig. 4. Locations of management areas (MAs) in risk contact with MA 3a through movement of live fish or bus-stop har-

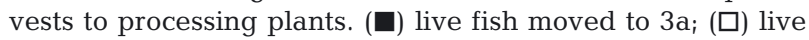
fish moved from $3 \mathrm{a}_{i}(\boldsymbol{\Lambda})$ bus stop to and from $3 \mathrm{a}_{i}(\Delta)$ bus stop to $3 \mathrm{a}_{i}(\bullet)$ fish farm; $(\bigcirc)$ processing plant. SPP: Scalloway processing plant; LPP: Lerwick processing plant. Shaded dark-grey areas represent an amalgamation of tidal excursions around the fish farms

\section{Equipment shared between sites}

Sites B, C and D belonged to company C2 (Table 1) and might have transferred infection via shared equipment (Scheel et al. 2007); however, FHIs found these sites had site-specific equipment and boats and there was no movement of fish between them (Fig. 3). Site A belonged to C1, Site E to C3 and Site F to C4, demonstrating that intra-company activity was not required for spread of ISAV. No transmission occurred to sites owned by company C1 other than Site A, even although biosecurity might have been less rigorously applied before ISA was confirmed.

\section{Harvest operations}

Processing plants. Salmon from sites in MA 3a were primarily processed at the SPP and LPP plants and both have advanced disinfection regimes in place which had been inspected by FHIs. The associated risk of ISAV spreading should be negligible, unless this disinfection failed (Jarp \& Karlsen 1997).

Between May and 11 December 2008, no fish from MA 3a were moved to the LPP. After this there was only a $3 \mathrm{wk}$ period before the notification of ISA on 2 January 2009, after which biosecurity should have been a very high priority. The LPP has facilities to hold live fish in open water cages on-site even though this is considered a high risk (Munro et al. 2003); however, fish were only held for short periods in these cages. A processing plant that held live fish on site was strongly statistically associated with the spread of ISAV in 1998-1999 (Murray et al. 2002).

The only site within $5 \mathrm{~km}$ of the LPP was tested at the 150-fish level and placed under bi-monthly surveillance due to the potential risk should disinfection have failed (Jarp \& Karlsen 1997); however, the fish at this site showed no evidence of infection. All sites near the SPP were already under monthly or bi-monthly inspections as they were within MA 3a.

Transport vessels. The transfer of fish to processing plants may risk transmission of infection (Munro et al. 2003). Each processing plant used single dedicated vessels for transporting harvest fish. A replacement vessel was used for taking harvest fish to the LPP from 8 to 27 August 2008; however, this was before material from MA 3a was processed and so the risk was considered to be negligible. This minimised the number of potentially contaminated vessels, although these 2 main vessels operated throughout Shetland.

The SPP received fish from only one source outside Shetland. This was from a site in Orkney which was harvested between March and June 2008, probably before infection became established at Site A, and was 
inspected by FHIs. All contacts for the LPP were within Shetland.

Bus stop harvesting. A 'bus stop' harvest involves collecting fish from 2 or more sites before delivery to the processing plant. This contravenes good practice where the disinfection of well boats between trips is required to minimise the risk of transmitting infection between sites. There were bus stop harvests to the SPP on at least 71 occasions in 2008 and some of these linked sites in MA 3a with other MAs (Fig. 4). Seven bus stop harvests involved Site A during September to November 2008 when ISAV may have been present, and one involved a site in another MA.

There were a further 5 bus stop harvests from MA 3a to $3 \mathrm{~b}$ and 7 from MA $3 \mathrm{~b}$ to $3 \mathrm{a}$, excluding the harvests involving the index site. There were 2 harvests from MA 4a (northwest Shetland) to 3a and also 2 from MA 2a (northeast Shetland) to 3a (Fig. 4). These bus stop harvests connect sites at the regional level; however, all the sites involved were inspected and there is no evidence of any association between vessels and ISA in this outbreak.

\section{Vertical transmission}

Movement of smolts. Some of the fish at the index site were derived from Norwegian ova, which are commonplace, with 28 million ova being imported to Scotland in 2008 (Walker 2009). These ova might be the source of infection; however, given that ISA seems to have appeared on site late in the production cycle, it is unlikely that infection was brought in with the ova. The ova were from certified disease free stocks and were disinfected both before export and on arrival in the UK.

Smolts were imported into MA 3a in 2008 from around Great Britain (Shetland, Western Isles, west coast and north east of Scotland and from Yorkshire, England), even though most sites in MA 3a did not input smolts that year (Fig. 3). The risk of spreading ISAV from MA 3a was considered negligible as fish are moved in, not out, and movements occurred before June 2008 when infection might have become established at Site A.

Movements of ova from Shetland. Vertical transmission might potentially spread ISA (Vike et al. 2009). The only broodstock site on Shetland is in MA $1 \mathrm{~b}$ (Fig. 4). The broodstock were in seawater until December 2008 and vessels from SPP visited sites in MA 1b in July, August and September 2008 when SPP was processing potentially infected material from MA 3a. This risk to broodstock is negligible unless disinfection at the SPP failed, and then a very low risk might have existed. There were no live fish movements or bus stop harvests into MA $1 \mathrm{~b}$ (Fig. 4).
Evidence for the occurrence of vertical transmission of ISAV is ambiguous (Lyngstad et al. 2008, Vike et al. 2009) and the broodstock in MA 1 b exhibited no signs of excessive mortality when inspected. Eggs were disinfected on 3 occasions during production and transfer; in these circumstances, and given the extremely low risk broodstock were exposed, the overall risk of vertical transmission is negligible assuming good biosecurity was practiced.

Wild and escaped fish

A total of 1196 wild marine fish were caught and sampled between 9 and 11 February 2009, including 446 from the vicinity of the then-infected Site B (Wallace et al. 2009). Kidney and gill samples were negative for ISAV using qPCR, so the brain and heart samples were not tested.

From the survey of wild fish caught from freshwaters during 23-25 March 2009, a total of 216 fish including 64 Atlantic salmon parr and 114 brown and sea trout were caught and screened (Wallace et al. 2009). A small number of the salmonids were fish farm escapees (Wallace et al. 2009). Kidney and gill samples from all these fish, tested individually by qPCR, were negative, so the heart and brain samples were not screened.

Gill samples from both the saithe taken from within a clinically infected cage at Site $C$ were positive for ISAV by qPCR (2/2); however, the kidney samples were ISAV-negative $(0 / 2)$, indicating exposure to but not infection with ISAV. Saithe are resistant to ISAV infection and clear themselves of this virus even under intraperitoneal (IP) challenge (Snow et al. 2002), so are unlikely to be effective carriers.

\section{Hydrodynamics and spread}

Hydrodynamic transport is a key factor in the spread of ISAV (Gustafson et al. 2007). All 6 cases were within overlapping excursion distances of each other, and Sites B, C and D were within one radius (Fig. 5). Sites E and $F$ may have been tertiary cases infected via an intermediate site. Alternatively, Site E is relatively close to the SPP and if the disinfection at this plant had failed, or if ISAV had been leaked from fish being unloaded at Scalloway pier for transport to LPP, it is possible that SPP could have been a source of infection at Site E (Munro et al. 2003). If this were the case, the transport of the virus from SPP would have been by water movements. Site F did give an early unconfirmed indication of infection, and this could indicate transport of the virus, perhaps at very low dose, outside the excursion radius. The management model, which uses overlap- 


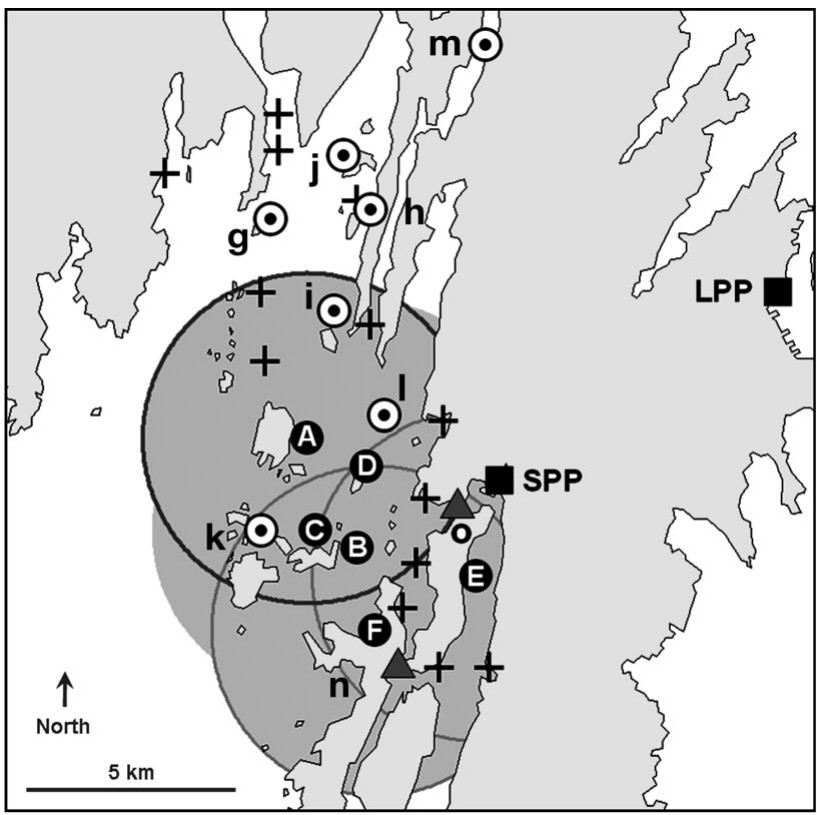

Fig. 5. Sites involved in the 2008-2009 infectious salmon anaemia (ISA) outbreak. Letters refer to sites listed in Table 1. SPP: Scalloway processing plant; LPP: Lerwick processing plant; (+) farms depopulated prior to the outbreak; $(\bullet)$ ISA-positive; $(\odot)$ ISA-negative; $(\boldsymbol{\Delta})$ non-susceptible species; ( $\square$ ) processing plant. Sites B, C and D are within $3.6 \mathrm{~km}$ of Site A (within darker circle line centred on Site A); Sites E and $\mathrm{F}$ are slightly further away, but well within overlapping excursion distances

ping radii to define an $\mathrm{MA}$, is thought to be robust enough to cope with this possibility.

Sites $\mathrm{i}, \mathrm{k}$ and $\mathrm{l}$ did not develop infection despite being within an excursion radius of Site $A_{i}$ however, these sites were all cleared within 2 mo of the ISA confirmation of Site A and so infection may not have had time to develop. Alternatively, local water current variability, which is not captured by the simple model used, may be responsible for localised circulation effects where virus is not transported to these sites from the infected sites.

The principle pattern of the outbreak is highly clustered with all cases within a few kilometres of each other and with later cases tending to be slightly further from the index site. This is the pattern expected from site-to-site spread via the environment and most likely by water movements, although it is possible additional factors might have played a role in this spread.

\section{CONCLUSIONS}

An outbreak of ISA has occurred in Scotland. Its origin is unknown but the virus differs in genogroup to that associated with a previous outbreak in 1998-1999.
Whether virulent ISAV evolved from a local avirulent HPR0 virus or was introduced via an unknown route, the event may repeat; therefore, even if eradication of virulent ISAV is achieved, good aquaculture husbandry and biosecurity remain important. The HPR0 strain has been detected on Scottish salmon farms (McBeath et al. 2009) and its eradication is unlikely to be cost-effective. Policies such as coordinated fallowing of MAs and the implementation of risk-based surveillance may prevent the re-establishment of ISAV in a virulent form.

Control of ISA requires quick responses by industry and the authorities; this requires rapid detection of the virus. Neither the 1998 nor the 2008 index cases were detected by active surveillance by inspectors, as the frequency of their routine surveillance inspections does not ensure early detection of disease. However, passive surveillance has been disappointing, with the 1998 index case reported only after the virus had had time to become widely dispersed (Murray et al. 2002), and the 2008 index case was not considered suspicious by site managers because mortality was attributed to sea lice infestations. However, detection was facilitated because the FHIs followed up general reports of mortality with diagnostic testing for a range of pathogens even though an alternative explanation was postulated. The Scottish Government is developing criteria for compulsory reporting of elevated fish mortality to more effectively target future surveillance resources.

The 2008-2009 ISA outbreak appears to have been localised, although it spread extensively within MA 3a. Other outbreaks including the 1998-1999 Scottish outbreak rapidly became widespread (Murray et al. 2002). Similarly outbreaks in Chile spread from Region X to Regions XI and XII and multiple clusters of local spread developed (Mardones et al. 2009). In Norway, ISA outbreaks were found in scattered clusters along the coast of the country, arguing for long-distance transmission of the virus (Lyngstad et al. 2008).

The use of strategic biosecurity-determined MAs by Marine Scotland Science for the purpose of disease control appears to have been effective at controlling ISA. Isolation has been maintained because of an absence of movements of fish to other MAs in the critical period and the disinfection of processing plant waste and harvest vessels. Depopulation of confirmed sites prevents these from acting as sources of infection as MAs cannot be completely hydrographically isolated.

A second line of defence existed in Scotland because no fish were moved between MA 3a and marine locations outside Shetland. Harvest vessels for SPP and LPP also collected fish only from Shetland, with one exception; therefore, had the MA biosecurity broken down, the risk from these processes would have been restricted to the regional level. 
Although ISAV was not detected in wild fish sampled early in the epidemic, except from the gills of saithe actually obtained from within an ISA-affected salmon cage, this does not mean they can be discounted. Given that wild fish can become ISAV vectors (Nylund \& Jakobsen 1995) and are capable of movement between sites (Uglem et al. 2009), they represent a potential risk so long as infection is allowed to remain. Escaped farm fish are likely to be even more effective vectors. Other wild animals such as grey seals Halichoerus grypus, which can travel at 75 to $100 \mathrm{~km}$ $\mathrm{d}^{-1}$ (McConnell et al. 1999), or parasites such as sea lice, which were abundant in the area, could also potentially transport ISAV (OIE 2009) beyond the MA boundaries.

There is no evidence that transmission of ISAV involving freshwater stages of production has occurred in this outbreak. Imports of ova are substantial, which could pose a risk if vertical transmission does occur. Long-distance movement of smolts from freshwater and the large numbers of movements between freshwater sites (Munro \& Gregory 2009) do spread other pathogens such as IPNV at the national or international levels (Ruane et al. 2009).

The case of Site F (and possibly Site D) suggests subclinical infection may have persisted at these sites for months. MA-wide movement restrictions and fallowing help manage the risk from undetected subclinical populations, and viral shedding from such populations is far lower than during clinical disease (Gregory et al. 2009), but spread could still occur, e.g. through escapes. A second possible explanation for the outbreak at Site $\mathrm{F}$ is persistence within an environmental reservoir; if this is the case, prolonged fallowing might be required to achieve eradication. In this respect, restocking did not begin until March 2010 so the MA had 4 mo of concurrent fallowing. The third possibility is an independent evolution of virulence (planned viral sequencing will address this). The most probable explanation appears to be subclinical infection and the effective detection of this may require diagnostic sampling in the absence of clinical signs.

Industry has played a key role in the design of good practice measures that prevented the spread from MA 3a (Anonymous 2000, CGPWG 2006) and this has been done in collaboration with the government. Costs of depopulation have been borne by individual fish farming companies. There have, however, been serious failings in the application of these controls. Movements of fish between sites were quite extensive in the first 6 mo of 2008 and, similarly, bus-stop harvesting, even between MAs, was practiced; both of these practices risk regional spread (Fig. 4). Smaller MAs defined for management convenience (CGPWG 2006) were not effective at controlling ISA, unlike those defined by hydrodynamics (Marine Scotland 2009). Some depopulation of confirmed sites was delayed, notably at Site D. Improvement on these practices should reduce the future risk from ISA.

With the clearance of the last site (Site F) in November 2009, this outbreak appears to have been successfully contained and eradicated. Industry began to repopulate 10 sites within MA 3a in spring 2010 and a program of surveillance of these sites to establish freedom from ISAV has begun. Industry behaviour combined with the speedy responses of Marine Scotland staff has confined the spread of ISA relative to other countries, or indeed Scotland as in the case of the 1998-1999 outbreak.

Acknowledgements. Data used for this paper was collected and analysed by Marine Scotland Science FHIs and scientists in the field and by diagnostic scientists in the Marine Laboratory, Aberdeen in support of the Scottish Government's ISA eradication programme. We thank the NAFC marine centre, fish farmers, processing plant and well boat operators, riparian owners, and the Shetland Anglers Association for their assistance.

\section{LITERATURE CITED}

Anonymous (2009) Infectious salmon anaemia confirmed in Shetland. Vet Rec 164:195

CGPWG (Code of Good Practice Working Group) (2006) A code of good practice for Scottish finfish aquaculture. Code of Good Practice Working Group, Scottish Salmon Producers Organisation, Perth

> Gregory A, Munro LA, Snow M, Urquhart KL, Murray AG, Raynard RS (2009) An experimental investigation on aspects of infectious salmon anaemia infection dynamics in seawater Atlantic salmon, Salmo salar L. J Fish Dis 32:481-489

Gustafson LL, Ellis SK, Beattie MJ, Chang BD and others (2007) Hydrographics and the timing of infectious salmon anemia outbreaks among Atlantic salmon (Salmo salar L.) farms in the Quoddy region of Maine, USA and New Brunswick, Canada. Prev Vet Med 78:35-56

Hastings T, Olivier G, Cusack R, Bricknell I and others (1999) Infectious salmon anaemia. Bull Eur Assoc Fish Pathol 19:286-288

Jarp J, Karlsen E (1997) Infectious salmon anaemia (ISA) risk factors in sea-cultured Atlantic salmon Salmo salar. Dis Aquat Org 28:79-86

Johansen LH, Sommer AI (2001) Infectious pancreatic necrosis virus infection in Atlantic salmon Salmo salar postsmolts affects the outcome of secondary infections with infectious salmon anaemia virus or Vibrio salmonicida. Dis Aquat Org 47:109-117

Joint Government/Industry Working Group on ISA (2000) Final report of the Joint Government/Industry Working Group on infectious salmon anaemia (ISA) in Scotland. Scottish Executive, Aberdeen

Lyngstad TM, Jansen PA, Sindre H, Jonassen CM, Hjortaas MJ, Johnsen S, Brun E (2008) Epidemiological investigations of infectious salmon anaemia (ISA) outbreaks in Norway 2003-2005. Prev Vet Med 84:213-227

Mardones FO, Perez AM, Carpenter TE (2009) Epidemiologic 
investigation of the re-emergence of infectious salmon anaemia virus in Chile. Dis Aquat Org 84:105-114

Marine Scotland (2009) Management Area Maps June 2009. Marine Scotland Marine Laboratory, Aberdeen, available at www.frs-scotland.gov.uk/FRS.Web/Uploads/Documents/ Management_Area_Maps_June2009.pdf

McBeath AJA, Bain N, Snow M (2009) Surveillance for infectious salmon anaemia virus HPR0 in marine Atlantic salmon farms across Scotland. Dis Aquat Org 87: 161-169

McClure CA, Hammell KL, Dohoo IR, Nérette P, Hawkins LJ (2004) Assessment of infectious salmon anaemia virus prevalence for different groups of farmed Atlantic salmon, Salmo salar L., in New Brunswick. J Fish Dis 27:375-383

McConnell BJ, Fedak MA, Lovell P, Hammond PS (1999) Movements and foraging areas of grey seals in the North Sea. J Appl Ecol 36:573-590

Munro LA, Gregory A (2009) Application of network analysis to farmed salmonid movement data from Scotland. J Fish Dis 32:641-644

Munro PD, Murray AG, Fraser DI, Peeler EJ (2003) An evaluation of the risks of infectious salmon anaemia transmission associated with different salmon harvesting methods in Scotland. Ocean Coast Manag 46:157-174

> Murray AG, Peeler EJ (2005) A framework for understanding the potential for emerging diseases in aquaculture. Prev Vet Med 67:223-235

Murray AG, Smith RJ, Stagg RM (2002) Shipping and the spread of infectious salmon anemia in Scottish aquaculture. Emerg Infect Dis 8:1-5

Murray AG, Amundrud TL, Gillibrand PA (2005) Models of hydrodynamic pathogen dispersal affecting Scottish salmon production: modelling shows how Scotland eradicated ISA, but not IPN. Bull Aquac Assoc Can 105:80-87

Nérette P, Hammell L, Dohoo I, Gardner I (2008) Evaluation of testing strategies for infectious salmon anaemia and implications for surveillance and control programs. Aquaculture 280:53-59

> Nylund A, Jakobsen P (1995) Sea trout as a carrier of infectious salmon anaemia virus. J Fish Biol 47:174-176

Nylund A, Devold M, Plarre H, Isdal E, Aarseth M (2003) Emergence and maintenance of infectious salmon anaemia virus (ISAV) in Europe: a new hypothesis. Dis Aquat Org 56:11-24

Nylund A, Plarre H, Karlsen M, Fridell F, Ottem KF, Bratland A, Saether PA (2007) Transmission of infectious salmon anaemia virus (ISAV) in farmed populations of Atlantic salmon (Salmo salar). Arch Virol 152:151-179

OIE (World Organisation for Animal Health) (2009) Infectious salmon anaemia. In: Manual of diagnostic tests for aquatic animals 2009. World Organisation for Animal Health, Paris, p 222-235

Raynard RS, Murray AG, Gregory A (2001) Infectious salmon anaemia virus in wild fish from Scotland. Dis Aquat Org 46:93-100

> Rodger H, Mitchell S (2007) Epidemiological observations of pancreas disease of farmed Atlantic salmon Salmo salar L. in Ireland. J Fish Dis 30:157-167

> Ruane NM, Murray AG, Geoghan F, Raynard RS (2009) Modelling the spread of infectious pancreatic necrosis virus (IPNV) in the Irish salmon farming industry: the role of inputs. Ecol Model 220:1369-1374

> Scheel I, Aldrin M, Frigessi A, Jansen PA (2007) A stochastic model for infectious salmon anemia (ISA) in Atlantic salmon farming. J R Soc Interface 4:699-706

> Snow M, Raynard R, Bruno DW, van Nieuwstadt AP, Olesen NJ, Løvold T, Wallace C (2002) Investigation into the susceptibility of saithe Pollachius virens to infectious salmon anaemia virus (ISAV) and their potential role as a vector for viral transmission. Dis Aquat Org 50:13-18

Snow M, McKay P, Matejusova I (2009) Development of a widely applicable positive control strategy for the detection of infectious salmon anaemia virus (ISAV) using Taqman real-time PCR. J Fish Dis 32:151-156

Stagg RM (2003) The eradication of an outbreak of clinical infectious salmon anaemia from Scotland. In: Miller O, Cipriano RC (eds) International response to infectious salmon anemia: prevention, control, and eradication: symposium proceedings, 3-4 Sep 2002, New Orleans, LA. Tech Bull 1902. US Department of Agriculture, Animal and Plant Health Inspection Service, US Department of the Interior, US Geological Survey, US Department of Commerce, National Marine Fisheries Service, Washington, DC, p 111-124

Totland GK, Hjeltnes BK, Flood PR (1996) Transmission of infectious salmon anaemia (ISA) through natural secretions and excretions from infected smolts of Atlantic salmon Salmo salar during their presymptomatic phase. Dis Aquat Org 26:25-31

Uglem I, Dempster T, Bjørn PA, Sanchez-Jerez P, Økland F (2009) High connectivity of salmon farms revealed by aggregation, residence and repeated movements of wild fish among farms. Mar Ecol Prog Ser 384:251-260

Vike S, Nylund S, Nylund A (2009) ISA virus in Chile: evidence of vertical transmission. Arch Virol 154:1-8

Walker A (2009) Scottish fish farms annual production survey 2008. Fisheries Research Services, Aberdeen

Wallace IS, Munro LA, Pert CC, McIntosh A, Kilburn R (2009) Shetland wild fish ISAV investigation. Marine Scotland Internal Report 18/09. Marine Scotland Science, Aberdeen

Submitted: February 23, 2010; Accepted: June 25, 2010

Proofs received from author(s): August 20, 2010
Editorial responsibility: Julie Bebak,

Auburn, Alabama, USA 